\title{
Clinical Instructors' Perceptions About the Characteristics of an Effective Clinical Instructor and Clinical Training Policies in Gaza Strip
}

\author{
Mahmoud Elkhateeb ${ }^{1, ~ *, ~ H a m z a ~ A b d e l j a w a d ~}{ }^{2}$ \\ ${ }^{1}$ Palestine College of Nursing, Ministry of Health, Gaza, Palestine \\ ${ }^{2}$ College of Health Professions, Al-Quds University, Gaza, Palestine
}

Email address:

El-khateeb-22@hotmail.com (M. Elkhateeb),Hamjawad1@gmail.com (H. Abdeljawad)

${ }^{*}$ Corresponding author

To cite this article:

Mahmoud Elkhateeb, Hamza Abdeljawad. Clinical Instructors' Perceptions About the Characteristics of an Effective Clinical Instructor and Clinical Training Policies in Gaza Strip. International Journal of Intelligent Information Systems. Vol. 9, No. 4, 2020 , pp. $39-43$. doi: $10.11648 /$ j.ijiis.20200904.13

Received: May 23, 2020; Accepted: June 15, 2020; Published: October 27, 2020

\begin{abstract}
The overall aim of this study is to assess the clinical instructors' perceptions about the characteristics of an effective clinical instructor and clinical training policies at the colleges that run bachelor of nursing programs in Gaza Strip. A descriptive-analytical cross-sectional study was used. The research participants were selected through quota sampling. The sample size included 182 clinical instructors from five colleges and universities. Self-administered questionnaires were distributed. Cronbach's alpha was calculated for the questionnaire by more than 0.7. Data were analyzed by using Statistical Package for Social Sciences (SPSS) version 23. The findings showed that the male clinical instructors represented $64 \%$ of the respondents while the female $36 \%$. The data indicated with regard to the qualifications of clinical instructors found that most of them had just a bachelor's degree (81.3\%) and the remaining had a master's degree (18.7\%). According to the results, the highest characteristic was "Professional Competence / Knowledge" with weighted mean 93.73\%, followed by "Communication" with weighted mean $89.07 \%$ and "Support the professional growth of students" in 3rd rank with weighted mean $87.87 \%$. While the most effective clinical training policies as perceived by clinical instructors were "The role of clinical training department in monitoring of instructors' performance with students is clear" with weighted mean $91.07 \%$, "The clinical instructor evaluates students in a fair and objective manner" with weighted mean $90.67 \%$, and "Selection of training site is relevant to achieve the clinical course objectives" with weighted mean $90.40 \%$. The study concluded that clinical nursing teaching is in need to improve its quality for both, the clinical instructors and policies.
\end{abstract}

Keywords: Clinical Instructors' Perceptions, Effective Clinical Instructor, Clinical Training Policies

\section{Introduction}

Clinical experience is an indispensable component of nursing curricula as it provides real-life experiences involving actual patients [1]. Clinical learning is considered as the heart of professional practice bridging the theory-practice divide [2] The integration of theoretical knowledge with clinical practice is of vital importance for the development of efficient professional nurses [3]. Both quality classroom teaching and ability in demonstrating clinical competence greatly influence the success of graduates of a nursing program [4].

A poorly trained nurse might hamper the team's effectiveness leading to ineffective nursing care $[5,6]$. Effective clinical teaching is critical for producing knowledgeable and skillful nurses who can deliver safe quality nursing services to individuals, families, and communities [7]. From the researcher experience as a clinical instructor, there is variability regarding the quality of effective clinical instructor and training policy characteristics as perceived by either clinical instructors or nursing students.

Clinical instructors have a critical role in the education and development of nursing students. They are responsible for ensuring student learning while acquiring clinical training experience to practice techniques. At the same time, clinical 
instructors are responsible for ensuring that patients receive high quality and safe nursing care $[8,9]$. Through reviewing literature, it was observed that most of the studies focused on the characteristics of the clinical instructor from the perspectives of nursing students, with few studies examining clinical instructors' opinions. Also, there were few studies exploring clinical instructors' perceptions about clinical training policies [10]. So, this study was done to assess clinical instructors' perceptions of the characteristics of an effective clinical instructor and their perceptions about effective clinical training policies.

\section{Methodology}

\subsection{Study Design}

A descriptive cross-sectional analytical design was used. This design is easy, inexpensive, quick and can target a large sample size in a short time and convenient to the researcher.

\subsection{Setting of the Study}

The study was carried out in Palestine College of Nursing, The Islamic University of Gaza, University College of Applied Sciences, Al-Israa University ,and Al-Azhar University.

\subsection{Sample Size and Sampling Procedure}

The research participants were selected through quota sampling, the population divided into homogeneous strata to ensure representation of the subgroups in the sample within each stratum subjects were sampled by convenience. The sample size included 182 clinical instructors.

\subsection{Pilot Study}

A pilot study of 20 students were taken to develop and test the adequacy of the research questionnaires and estimate the time needed to fill the questionnaire and check the feasibility of the study, and to make modifications in the questionnaires as needed. The pilot study was excluded from the final sample.

\subsection{Ethical Considerations}

Written informed consent was obtained from all participants. Ethical approval to conduct the study was obtained from the Helsinki Committee and administrative permission was obtained from each academic institution.

\subsection{Eligibility Criteria}

The study included the clinical instructors who have two years or more of experience in training undergraduate nursing students from Palestine College of Nursing, The Islamic University of Gaza, University College of Applied Sciences, Al-Israa University, and Al-Azhar University.

\subsection{Study Tools and Instruments}

The questionnaire adapted from [11]. The questionnaire adapted for measuring clinical instructors' perceptions which divided into 3 parts. Part 1 consisted of demographic data of respondents, part 2 about clinical instructors' characteristics while part 3 about effective training policies. The second part had 36 items divided into 7 subdomains (professional competence/knowledge, supporting professional growth of students, effective clinical evaluation, communication, academic responsibilities, teaching/training skills and clinical instructor-student relationship) for determining effective clinical instructor characteristics while the third part consisted of 16 items divided into 3 subdomains (planning of training, implementation of training and evaluation of training) for determining effective clinical training policies. The questionnaire used the five points Likert Scale for measuring the second and third parts ranging from strongly disagree to strongly agree.

\subsection{Reliability and Validity of the Questionnaires}

The questionnaire was evaluated by five experts. The reliability of both questionnaires was checked through the pilot study. Cronbach's alpha was 0.951 .

\subsection{Data Collection}

The data was collected through self-administered questionnaires. Data collection was done from 15/10/2019 to $8 / 11 / 2019$. The response rate was $82.4 \%$.

\subsection{Statistical Analysis}

Data were analyzed by using Statistical Package for Social Sciences (SPSS) version 23. Descriptive (mean, standard deviation and percentage) and inferential (T-test and One-way ANOVA) statistical tests were used as appropriate. P-values of $\leq 0.05$ was considered statistically significant.

\section{Results}

\subsection{Demographic Characteristics of the Study Population}

Table 1 presented that the highest percentage of clinical instructors were aged between $25-35$ years $(58 \%)$, while $(28 \%)$ of them between 36-45 years and the remaining between 46-60 years (14\%). In addition, (64\%) of clinical instructors were male and (36\%) female. Moreover, $(88 \%)$ of them were married and just $12 \%$ were single. The highest percentage of clinical instructors had just a bachelor's degree $(81.3 \%)$ and (18.7\%) had a master's degree. Most of the clinical instructors got training courses related to clinical training (90.7\%) and 14 $(9.3 \%)$ did not get it.

Table 1. Socio-Demographic characteristics of the study population.

\begin{tabular}{llll}
\hline Variables & & Number & Percentage (\%) \\
\hline \multirow{2}{*}{ Gender } & Male & 96 & 64.0 \\
& Female & 54 & 36.0 \\
\hline
\end{tabular}




\begin{tabular}{llll}
\hline Variables & & Number & Percentage (\%) \\
\hline \multirow{3}{*}{ Age groups } & $25-35$ years & 87 & 58.0 \\
& $36-45$ years & 42 & 28.0 \\
Marital status & $46-60$ years & 21 & 14.0 \\
& Single & 18 & 12.0 \\
Qualifications & Married & 132 & 88.0 \\
& Bachelor degree & 122 & 81.3 \\
Having training courses & Master degree & 28 & 18.7 \\
& Yes & 136 & 90.7 \\
Years of experience & No & 14 & 9.3 \\
& $2-5$ years & 63 & 42.0 \\
& 6-10 years & 69 & 46.0 \\
& $11-15$ years & 18 & 12.0 \\
University/ College & Palestine College of Nursing & 10 & 6.7 \\
& Islamic University of Gaza & 55 & 36.7 \\
& Al-Azhar University & 12 & 8.0 \\
& Al-Israa University & 13 & 8.7 \\
& University College of Applied Sciences & 60 & 40.0 \\
\hline
\end{tabular}

\subsection{Distribution of the Clinical Instructors According to Their Perception About the Characteristics of an Effective Clinical Nursing Instructor Domain (7 Characteristics)}

Table 2 showed that the total mean for characteristics of an effective clinical nursing instructor was 4.42 and the total weighted percentage of the mean was $88.47 \%$. According to the results, the highest characteristic was
"Professional Competence / Knowledge" with weighted mean $93.73 \%$, followed by "Communication" with weighted mean $89.07 \%$ and "Support the professional growth of students" in $3^{\text {rd }}$ rank with weighted mean $87.87 \%$. While the lowest three characteristics were "Clinical instructor relationship with the student", "Academic responsibility" and subdomain "Teaching / Training Skills" with weighted mean $86.87 \%, 86 \%$ and $85.13 \%$ respectively.

Table 2. Ranking of the effective clinical instructor characteristics as perceived by clinical instructors.

\begin{tabular}{lllll}
\hline Characteristics of an Effective Clinical Nursing Instructor & Mean & Standard Deviation & \% & Rank \\
\hline Professional Competence / Knowledge & 4.69 & 0.45 & 93.73 & 1 \\
Communication & 4.45 & 0.52 & 89.07 & 2 \\
Support the professional growth of students & 4.39 & 0.48 & 87.87 & 3 \\
Effective clinical evaluation & 4.35 & 0.53 & 86.93 & 4 \\
Clinical instructor relationship with the student & 4.34 & 0.66 & 86.87 & 5 \\
Academic responsibility & 4.30 & 0.47 & 86 & 6 \\
Teaching / Training Skills & 4.26 & 0.52 & 85.13 & 7 \\
Total & 4.42 & 0.58 & 88.47 & \\
\hline
\end{tabular}

\subsection{Distribution of the Clinical Instructors According to Their Perception About Effective Clinical Training Policies Domain (16 Items)}

According to the findings of table 3, item "Selection of training site is relevant to achieve the clinical course objectives" has the highest rank $91.07 \%$, followed by item "The clinical instructor evaluates students in a fair and objective manner" with weighted mean $90.67 \%$, item
"Selection of training site is relevant to achieve the clinical course objectives" in 3rd rank with weighted mean $90.40 \%$, item "The clinical training department gives instructors clear directions about the objectivity in evaluating their students" in 4th rank with weighted mean $89.87 \%$ and item "The role of training department in monitoring students' clinical training is obvious" in 5 th rank with weighted mean $89.20 \%$.

Table 3. Top five perceived effective clinical training policies.

\begin{tabular}{|c|c|c|c|c|}
\hline Clinical Training Policies & Category & Mean (SD) & $\%$ & Rank \\
\hline $\begin{array}{l}\text { The role of clinical training department in monitoring of instructors' performance with } \\
\text { students is clear. }\end{array}$ & Evaluation of training & $4.55(0.59)$ & 91.07 & 1 \\
\hline The clinical instructor evaluates students in a fair and objective manner. & Evaluation of training & $4.53(0.66)$ & 90.67 & 2 \\
\hline Selection of training site is relevant to achieve the clinical course objectives. & Planning of training & $4.52(0.66)$ & 90.40 & 3 \\
\hline $\begin{array}{l}\text { The clinical training department gives instructors clear directions about the objectivity in } \\
\text { evaluating their students. }\end{array}$ & Evaluation of training & $4.49(0.63)$ & 89.87 & 4 \\
\hline The role of clinical training department in monitoring students' clinical training is obvious. & Evaluation of training & $4.46(0.67)$ & 89.20 & 5 \\
\hline
\end{tabular}




\section{Discussion}

The results showed that the highest characteristic was "Professional Competence / Knowledge" and this agreed with the study stated that nursing competence was the clinical instructor characteristic that had the highest rating by clinical instructors [12]. Another study indicated that the categories of teaching ability and interpersonal relationships were the most valued characteristics and the least valued characteristics rated by clinical instructors were the categories of nursing competence rated by clinical instructors and this inconsistent with the current findings [10]. These differences could be attributed to differences in the research design, the educational needs and facilities and the nursing education curricula, particularly clinical teaching.

The results also showed that the important effective clinical training policies from perception of clinical instructors is located in evaluation category. A study mentioned that as a part of the overall planning process in a teaching session, the clinical instructor has to define his/her aims of the session, the learning outcomes or objectives, and an evaluation [13]. Another study revealed that the most important clinical evaluation problem was the lack of a comprehensive, objective and appropriate evaluation tool for assessing the students. It seems that the duration of the clinical course is short and most clinical instructors are busy during each semester. Consequently, they used most of their time in clinical teaching and complained about their limited time for clinical evaluation; therefore, they did not have time to identify the students' clinical competencies [14]. Also, another study stated that the challenges for effective evaluation of nursing education included ambiguity in evaluation's aims, uncertainty in evaluation expectations and unqualified evaluators regarding inexpert, disinterest and biased evaluators, which consequently cause inefficacy of evaluation process [15]. All of these studies were in agreement with the results of the present study that the clinical training department has a big role in evaluating the training process through giving instructors clear directions about the objectivity in evaluating their students, monitoring of instructors' performance with students and monitoring students' clinical training.

It is obvious from the results of this table that clinical instructors are more concerned with evaluation policies than planning and implementation policies. The researcher believes that this may attributed to the difficulties faced by clinical instructors in the evaluation process due to lack of clear policies regarding the evaluation process, the lack of clarity of the evaluation tool, and the lack of good follow-up from the clinical training department.

\section{Recommendations}

Based on the results of this study, it is recommended to:

1. Develop specific criteria for the selection of future clinical instructors included professional competence and communication skills as a basis of selection.

2. Establish programs for clinical instructors to develop their knowledge, training, and evaluating skills.

3. Develop a standardized evaluation form to support and fairly evaluate the students by the clinical instructors within the clinical setting since that is the common concern of clinical instructors.

4. The nursing faculties should take into consideration the viewpoints of clinical instructors about the characteristics of an effective clinical instructor and clinical training policies because they are one of the main stakeholders in the training process.

5. Establish clear guidelines regarding the role of the clinical training department in monitoring the performance of clinical instructors and students.

6. Clinical instructors need to become familiar with clinical evaluation methods and to use them to improve students' learning in clinical settings.

\section{Conclusion}

This study aimed to assess the clinical instructors' perceptions about the characteristics of an effective clinical instructor and clinical training policies at the colleges that run bachelor of nursing programs in Gaza Strip This descriptive, analytic, cross-sectional study included 182 clinical instructors from five universities and colleges. The results showed that the most important characteristics of an effective instructor from the viewpoint of the clinical instructor were professional competence, communication and support the professional growth of students with weighted mean $93.73 \%, 89.07 \%$, and $87.87 \%$ respectively. While the most important clinical training policies as perceived by the clinical instructors were the role of training department in monitoring of instructors' performance with students must be clear, objective evaluation, appropriate selection of training site, clear directions about the objectivity in evaluating students from the clinical department and clarity in the role of training department about monitoring students' clinical training with weighted mean $91.07 \%, 90.67 \%, 90.405,89.87 \%$, and $89.20 \%$ respectively. The study emphasize that clinical nursing teaching is in need to improve its quality for both, the clinical instructors and policies.

\section{Disclosures}

All the authors do not have any possible conflicts of interest.

\section{References}

[1] Tiwaken, S. U., Caranto, L. C., \& David, J. T. (2015). The Real World: Lived Experiences of Student Nurses during Clinical Practice. Retrieved September 10, 2019, from http://article.sapub.org/10.5923.j.nursing.20150502.05.html. 
[2] Lewin, D. (2007). Clinical Learning Environments for Student Nurses: Key Indices From Two Studies Compared Over a 25 Year Period. Retrieved August 3, 2019, from https://pubmed.ncbi.nlm.nih.gov/17689449/.

[3] Kaphagawani, N. C., \& Useh, U. (2013). Analysis of Nursing Students Learning Experiences in Clinical Practice: Literature Review. Retrieved October 5, 2019, from https://www.researchgate.net/publication/286124234 Analysi s_of_Nursing_Students_Learning_Experiences_in_Clinical_P ractice_Literature_Review.

[4] Dasila, P. K., Veer, B. V., Ponchitra, R., Divya, K. Y., \& Setia, M. S. (2016). Perceptions Of Nursing Students On Clinical Teaching Behaviors Of Teaching Faculty: Correlational Survey Design. Journal of Nursing and Health Science, 5 (5), 37-41. doi: 10.9790/1959-0505063741.

[5] Tamara, L., Buchel, T. L. and Edwards, F. D. (2005) Characteristics of effective clinical teachers. Family Medicine, 37, 30-35.

[6] Levy, L. S., Sexton, P., Willeford, K. S., Barnaum, M. G., Guyer, M. S., Gardner, G. and Fincher, A. L. (2009) Clini- cal instructor characteristics, behaviours and skills in al- lied healthcare settings: A literature review. Athletic Train- ing Educational Journal, 4, 8-13.

[7] Okoronkwo, I. L., Onyia-Pat, J., Agbo, M. E., Okpala, P. U., \& Ndu, A. C. (2013). Students' perception of effective clinical teaching and teacher behaviour. Open Journal of Nursing, 03 (01), 63-70. doi: 10.4236/ojn.2013.31008.

[8] Chiang, H. (2005): Students' perceptions of effective and ineffective clinical instructors. Journal of Nursing Education, 44 (4), 187-192.
[9] Rehan, S. and Barolia, R. (2007): Characteristics of Clinical Faculty Perceived by Nursing Students and Alumni in Karachi. Canadian Journal of Pure and Applied Sciences. 1 (1). 35-44.

[10] EL Banan, S. H. A. E., \& Elsharkawy, N. B. (2017). Undergraduate Nursing Students' and Clinical Instructors' Perceptions of the Characteristics of an Effective Clinical Instructor at the Faculty of Nursing, Cairo University. American Journal of Nursing Science, 6 (3), 185-192. doi: 10.11648/j.ajns.20170603.16.

[11] Gardner, M., \& Suplee, P. (2009). Handbook of clinical teaching in nursing and health sciences (1st ed.). Jones \& Bartlett Publishers.

[12] Soriano, G. P., \& Aquino, M. (2017). Characteristics of a Good Clinical Teacher as Perceived by Nursing Students and Faculty Members in a Philippine University College of Nursing. Retrieved from http://article.sapub.org/10.5923.j.nursing.20170704.04.html.

[13] McKimm, J., \& Swanwick, T. (2009). Assessing Learning Needs. Retrieved October 29, 2019, from https://pubmed.ncbi.nlm.nih.gov/19516213/.

[14] Rafiee, G., Moattari, M., Nikbakht, A. N., Kojuri, J., \& Mousavinasab, M. (2014). Problems and challenges of nursing students' clinical evaluation: A qualitative study. Retrieved October 29, 2019, from https://www.ncbi.nlm.nih.gov/pmc/articles/PMC3917184/\#ref 20.

[15] Khodaveisi, M., Pazargadi, M., Yaghmaei, F., \& Bikmoradi, A. (2012, July). Identifying challenges for effective evaluation in nursing education: A qualitative study. Retrieved October 29, 2019 , https://www.ncbi.nlm.nih.gov/pmc/articles/PMC3685791/. 